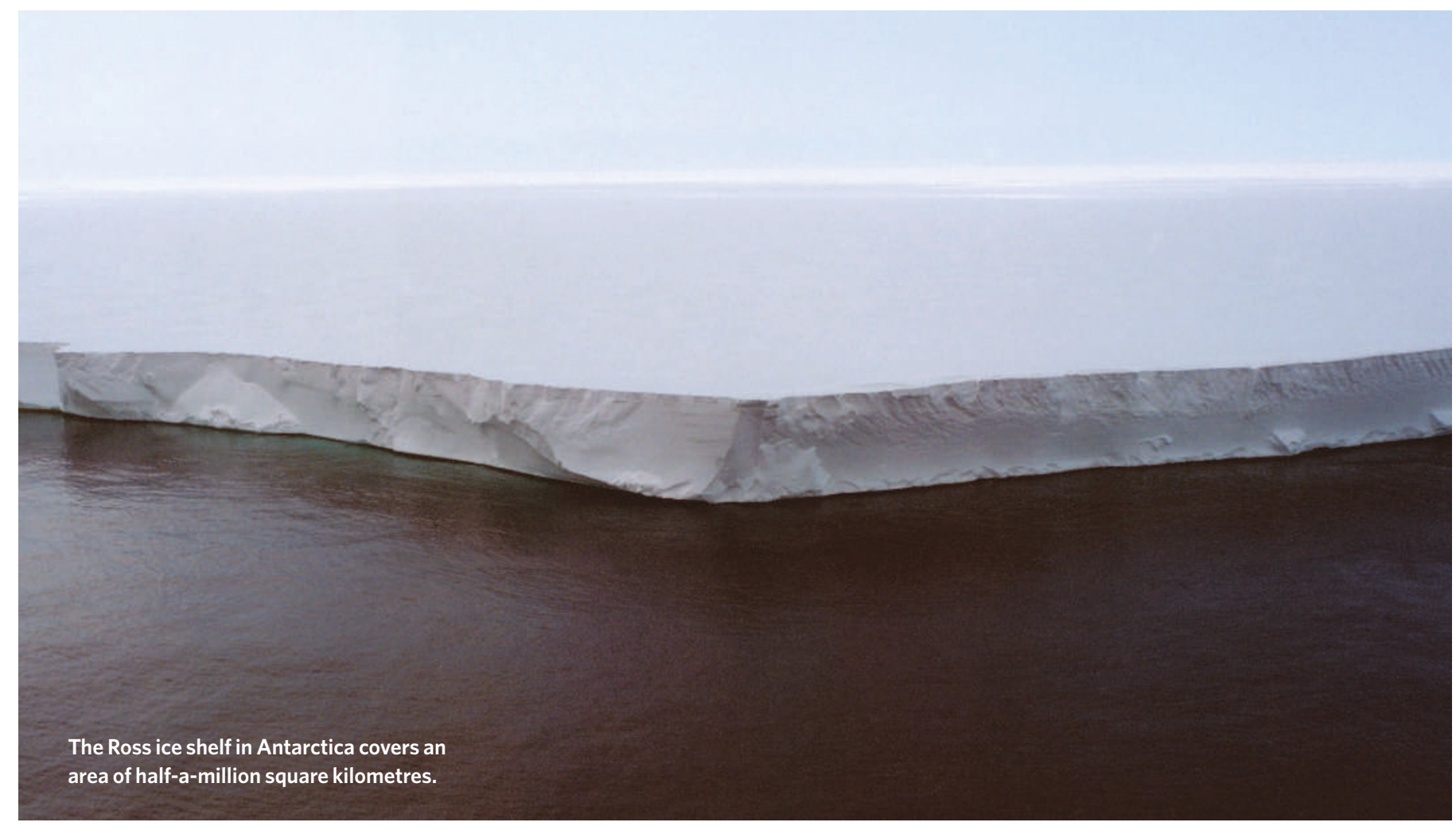

\title{
Journey to the end of the Earth
}

\section{Terra Antarctica: Looking Into the Emptiest Continent \\ by William L. Fox \\ Trinity University Press: 2005. 304 pp. $\$ 35$}

\section{Lloyd Peck}

Given the inaccessibility and mystery of Antarctica, it is not difficult to see why the continent inspired writers such as Edgar Allan Poe and Jules Verne to set novels in a fictitious ice-bound land with hot plateaux where dinosaurs persist, and deep craters that provide access to the centre of the Earth. Antarctica certainly poses a challenge for the imagination of anyone who contemplates its vast beauty. In Terra Antarctica, William Fox aims to show how we use cultural means to augment our neurobiology in overcoming the perceptual difficulties we experience when exploring this huge, largely deserted continent.

The book itself is an eclectic journey. It melds a series of deeply intense personal experiences in Antarctica with well-researched vignettes on the history or development of artistic or cartographic representation. This is then put into the context of our current view of Antarctica and of the science done there. This can, at times, seem like a bizarre combination. Juxtaposed with awe-inspiring descriptions of the landscape are, for example, sections on the degree angular scale interferometer, which measures microwave background radiation and provides insight into the shape of the Universe and what it was like in its early stages.

Polynesian history is also included, as the Polynesians are thought to have been the first to discover the Antarctic. According to their oral history, Ui-te-Rangiora sailed south to a place where the sea was white and dangerous, a voyage that probably took place around AD 650, more than 1,000 years before Western civilization found the continent. This then contrasts with a detailed description of the influence of the painter J. M. W. Turner on the representation of landscape in art and the development of photographic methods to document landscape. This style of presentation may not be to everyone's taste.

Clearly, drawing together such a great diversity of subjects is more than a challenge. Fox does it well, making good use of his Antarctic experiences, and there is much genuine awe in his responses during his visits to research sites at McMurdo and Pole stations, and also to the driest deserts on Earth and the most southerly active volcano, Mount Erebus.

The historic elements, the descriptions of how the methodology developed, and the detailed science concepts are written in a clear and accessible manner that will bring the subjects into deep relief for many. The direction of the plot is more erratic than in books on a set science or arts subject, however. There are also some enthralling impressions of a landscape that is clearly a challenge to encompass, even for someone with Fox's powerful ability to paint verbal pictures. I liked his description of the seemingly endless variety of ice in Lake Vanda that Fox claims left him dumbstruck (a common response to Antarctica's ability to go beyond the human imagination) as he stood surrounded by acres of glass-clear ice fractured into amazingly intricate geometries. This section is written almost as a religious experience in which, standing on the ice, the feeling is of flying in a dream. Descriptions of glass-corroding acid clouds on Mount Erebus, and tent-toppling storms with 85-mile-anhour winds that hurl golf-ball-sized pebbles at you, are more the stuff of Antarctic lore, but they are still gripping and fantastical to those who have not seen them.

Readers interested in how humans have struggled with nature to develop techniques to master the inaccessibility of the world around them will want this book on their shelves. Those whose feet are more firmly entrenched in the real world, and who eschew a metaphysical approach to understanding the world, may be frustrated by the eclectic nature of the content. Those in between will find some things they like or cherish, and some that pass them by.

In the end, Antarctica is too much for even the greatest wordsmiths' use of language, the greatest painters' palettes, and the greatest photographers' use of light and composition. Fox gives us an enthralling guided tour of the human mind's attempt to make space into place, and land into landscape. But for me, at least, Antarctica remains beyond the reach of human arts.

Lloyd Peck is at the British Antarctic Survey, High Cross, Madingley Road, Cambridge CB3 OET, UK. 